\title{
Abnormal ghrelin secretion contributes to gastrointestinal symptoms in multiple system atrophy patients
}

\author{
Tetsutaro Ozawa $\cdot$ Jun Tokunaga $\cdot$ Musashi Arakawa $\cdot$ Atsushi Ishikawa $\cdot$ Ryoko Takeuchi $\cdot$ \\ Naomi Mezaki · Takeshi Miura Naoko Sakai - Mariko Hokari • Akari Takeshima • \\ Kota Utsumi · Takashi Kondo · Akio Yokoseki · Masatoyo Nishizawa
}

Received: 23 February 2013/Revised: 26 April 2013/Accepted: 27 April 2013/Published online: 8 May 2013

(C) The Author(s) 2013. This article is published with open access at Springerlink.com

\begin{abstract}
Patients with multiple system atrophy (MSA) often have evidence of compromised gastrointestinal motility. Ghrelin is a gut hormone that influences gastrointestinal motility in humans. The aim of this study was to determine whether ghrelin secretion is affected in MSA patients, and to investigate the relation between ghrelin secretion and gastrointestinal symptoms. Plasma levels of active ghrelin and unacylated ghrelin were measured in patients with MSA $(n=30)$, other atypical parkinsonian disorders including progressive supranuclear palsy-Richardson syndrome and corticobasal syndrome $(n=24)$, and control subjects $(n=24)$ using enzyme-linked immunosorbent assays. Gastrointestinal symptoms were quantified in all subjects using a self-report questionnaire. The ratio of active ghrelin to total ghrelin in the plasma (active ghrelin ratio) was lower in patients with MSA (mean: $8.0 \%$ ) than in patients with other atypical parkinsonian disorders (mean: $13.7 \%, P=0.001$ ) and control subjects (mean: $13.9 \%, P=0.001)$. The active ghrelin ratio was correlated with the severity of gastrointestinal symptoms in MSA $(r=-0.5, P=0.004)$. Our observations indicate that ghrelin secretion is affected in patients with MSA. The low active ghrelin ratio may contribute to gastrointestinal symptoms in MSA.
\end{abstract}

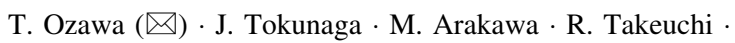

N. Mezaki - T. Miura - N. Sakai - M. Hokari - A. Takeshima ·

K. Utsumi · A. Yokoseki · M. Nishizawa

Department of Neurology, Brain Research Institute, Niigata

University, 1 Asahimachi-dori Chuoku, Niigata 951-8585, Japan

e-mail: ozawa@bri.niigata-u.ac.jp

A. Ishikawa $\cdot$ T. Kondo

Department of Neurology, Brain Disease Center Agano Hospital,

6317-15 Yasuda, Agano, Niigata 959-2221, Japan
Keywords Multiple system atrophy $\cdot$ Progressive supranuclear palsy $\cdot$ Corticobasal syndrome $\cdot$ Autonomic dysfunction · Ghrelin · Gastrointestinal symptom

\section{Introduction}

Nonmotor symptoms have a strong impact on the prognosis and quality of life in patients with multiple system atrophy (MSA). Patients with MSA often have evidence of compromised gastrointestinal motility $[1,2]$, which may be caused by disruptions in the autonomic nervous system. However, it remains unclear whether neurohormonal function contributes to compromised gastrointestinal motility in MSA.

Ghrelin is a gut hormone that acts as a natural ligand for the growth hormone secretagogue receptor. It plays an important role in the neurohormonal interaction between the gastrointestinal tract and the central nervous system [3]. Ghrelin has been reported to influence gastrointestinal motility in humans $[4,5]$. The aim of the present study was to determine whether ghrelin secretion is affected in patients with MSA, and to investigate the relation between ghrelin secretion and gastrointestinal symptoms in these patients.

\section{Methods \\ Subjects}

Subjects were 30 patients with probable MSA (21 patients with MSA-C and 9 patients with MSA-P), 24 patients with other atypical parkinsonian disorders (13 patients with progressive supranuclear palsy-Richardson syndrome and 
11 patients with corticobasal syndrome), and 24 control subjects (16 patients with non-neurodegenerative diseases and 8 healthy individuals). The 16 subjects with non-neurodegenerative diseases consisted of three patients with peripheral neuropathy, three patients with idiopathic normal pressure hydrocephalus, four patients with cervical spondylosis, and six post-stroke patients undergoing rehabilitation. Neurologists specialized in movement disorders clinically diagnosed the patients with MSA and other atypical parkinsonian disorders in accordance with established or proposed diagnostic criteria for the diseases [6-8]. The levodopa-equivalent daily dose of anti-parkinsonian medication was calculated as described previously [9]. None of the patients with MSA or other atypical parkinsonian disorders were receiving anticholinergic therapies. Dementia was not a criterion for exclusion, because patients with other atypical parkinsonian disorders may have associated dementia. Body mass index was evaluated in each subject. No drugs that are known to affect ghrelin secretion in human, namely, olanzapine [10], flutamide [11], estrogen [12], somatostatin [13], growth hormone [14], insulin-like growth factor-I [12], and rikkunshito [15], were administered to the subjects before blood sampling. None of the subjects had alcoholism, diabetes mellitus, inflammatory bowel diseases, or cancer-induced cachexia. Informed consent was obtained from all subjects. The protocol of this study was approved by the Ethics Committee at Niigata University School of Medicine, and was carried out in accordance with the Declaration of Helsinki.

\section{Assessment of gastrointestinal symptoms}

The gastrointestinal domain of the scales for outcomes in Parkinson's disease-autonomic (SCOPA-AUT) [16] was used to assess gastrointestinal symptoms. This is composed of seven questions about gastrointestinal symptoms, namely, swallowing/choking, sialorrhea, dysphagia, early abdominal fullness, constipation, straining for defecation, and fecal incontinence. A symptom was considered present (gaining 1 point) if the patient reported that it had occurred regularly or often in the past month, and the severity of gastrointestinal symptoms was rated by the total SCOPAAUT gastrointestinal score (range 0-7 points).

\section{Blood sampling and hormone assays}

On the day prior to blood sampling dinner was served at $1800 \mathrm{~h}$ and the time of lights out was set at $2100 \mathrm{~h}$. Subjects were asked to stay in bed from lights out until the time of blood sampling the next morning, except for visits to the toilet. Bedrooms used in this study were in quiet surroundings and set at a comfortable room temperature between 18 and $25^{\circ} \mathrm{C}$ throughout the night. These settings were selected to avoid sleep deprivation that could affect ghrelin secretion [17]. Blood samples were obtained from subjects the morning after a $12 \mathrm{~h}$ fast. To avoid the influence of food intake [18] and visual or olfactory stimulus of food on ghrelin secretion, subjects were not permitted to eat between meals and breakfast was served after blood sampling. To avoid the effect of alcohol intake on ghrelin secretion, subjects were instructed to abstain from drinking beverages that contained alcohol during the study period [19].

Blood samples were immediately transferred to polypropylene tubes containing $\mathrm{Na}_{2}$ EDTA and aprotinin, and then centrifuged at $3,500 \mathrm{rpm}$ for $10 \mathrm{~min}$. Immediately after centrifugation, one-tenth of the volume of $1 \mathrm{~N} \mathrm{HCl}$ was added to the separated plasma. There are two circulating forms of ghrelin, acylated (active) ghrelin with $n$ octanoylation at serine three and unacylated ghrelin. The plasma levels of active ghrelin and unacylated ghrelin were measured using commercially available enzyme-linked immunosorbent assay kits according to the manufacturer's instructions (active ghrelin and desacyl-ghrelin ELISA kit, Mitsubishi Kagaku Iatron Inc., Tokyo, Japan). The sensitivity of the applied methods was $4 \mathrm{fmol} / \mathrm{ml}$ for active ghrelin and $14 \mathrm{fmol} / \mathrm{ml}$ for unacylated ghrelin. The intraand interassay coefficients of variation were 5.5 and $4.9 \%$ respectively for active ghrelin, and 4.7 and $8.6 \%$ respectively for unacylated ghrelin. The ratio of active ghrelin to total ghrelin in the plasma (active ghrelin ratio) was obtained using the following formula:

Active ghrelin $/$ (Active ghrelin + Unacylated ghrelin) $\times 100(\%)$.

\section{Statistical analyses}

One-way analysis of variance was used to compare variables across the three groups. Significant main effects of group were followed by post hoc comparisons with Bonferroni corrections. T-tests were used to compare variables across two groups. A $\chi^{2}$ test was used to compare sex distribution across the three groups. Pearson's correlation coefficient was used to quantify the relation between the SCOPA-AUT gastrointestinal score and the active ghrelin ratio in each group. Values of $P<0.05$ were considered significant.

\section{Results}

Age at the time of evaluation, sex distribution, and body mass index were matched across the three groups, and disease duration and levodopa equivalent daily doses were matched for the two patient groups (Table 1). The SCOPAAUT gastrointestinal score was significantly higher in the 
Table 1 Subjects' demographic characteristics and state of ghrelin secretion

\begin{tabular}{|c|c|c|c|c|}
\hline & MSA & Other APD & Control & $P$ value \\
\hline Number of cases & 30 & 24 & 24 & \\
\hline Age (years) & $67.5(1.6)$ & $73.1(1.3)$ & $67.5(3.0)$ & 0.1 \\
\hline Male:female & $16: 14$ & $15: 9$ & $15: 9$ & $>0.5$ \\
\hline Disease duration (years) & $4.3(0.5)$ & $3.9(0.7)$ & Not applicable & 0.64 \\
\hline Levodopa equivalent daily doses (mg/day) & $130.6(40.0)$ & $135.0(38.4)$ & Not applicable & 0.93 \\
\hline Body mass index $\left(\mathrm{kg} / \mathrm{m}^{2}\right)$ & $21.2(0.6)$ & $21.5(0.8)$ & $22.1(0.6)$ & 0.6 \\
\hline SCOPA-AUT gastrointestinal score & $3.8(0.3)$ & $2.1(0.2)$ & $0.5(0.1)$ & $0.001 *$ \\
\hline Active ghrelin $(\mathrm{fmol} / \mathrm{ml})$ & $6.9(0.9)$ & $10.2(1.3)$ & $11.2(1.7)$ & 0.05 \\
\hline Unacylated ghrelin $(\mathrm{fmol} / \mathrm{ml})$ & $102.2(15.8)$ & $69.9(10.3)$ & $66.8(8.1)$ & 0.08 \\
\hline Active ghrelin ratio $(\%)$ & $8.0(0.8)$ & $13.7(1.1)$ & $13.9(0.9)$ & $0.001 * *$ \\
\hline
\end{tabular}

Data are $n$ or mean (standard error)

MSA multiple system atrophy, APD atypical parkinsonism disorder, SCOPA-AUT scales for outcomes in Parkinson's disease-autonomic

* Post-hoc $P$ values (after Bonferroni correction): MSA vs. other APD; $P=0.001$, MSA vs. control; $P=0.001$, other APD vs. control; $P=0.002$

** Post-hoc $P$ values (after Bonferroni correction): MSA vs. other APD; $P=0.001$, MSA vs. control; $P=0.001$, other APD vs. control; $P=1.0$

MSA group than in the other two groups (Table 1). Although the levels of plasma active ghrelin and unacylated ghrelin did not differ between the three groups, the active ghrelin ratio was significantly lower in the MSA group than in other two groups (Table 1). The active ghrelin ratio was very similar in the atypical parkinsonian and control groups (Table 1). In the control group, there was no difference in active ghrelin ratio between the 16 patients with non-neurodegenerative diseases (mean: $13.6 \%$ ) and 8 healthy individuals (mean: $14.4 \%, P=0.7$ ).

In the MSA group, the active ghrelin ratio was significantly correlated with the SCOPA-AUT gastrointestinal score $(r=-0.5, P=0.004$; Fig. 1$)$, such that a lower active ghrelin ratio was associated with more gastrointestinal

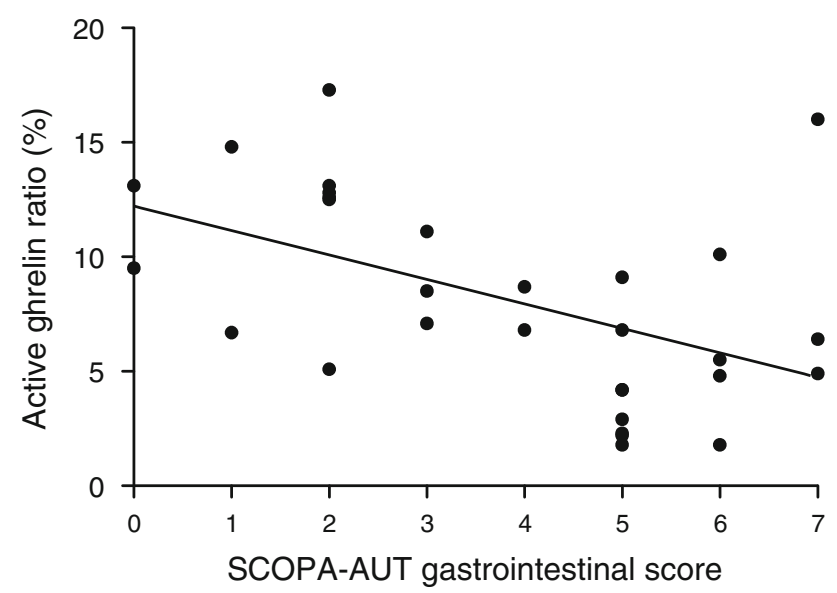

Fig. 1 The relation between the ratio of active ghrelin to total ghrelin in the plasma (active ghrelin ratio) and the scales for outcomes in Parkinson's disease-autonomic (SCOPA-AUT) gastrointestinal score in patients with MSA $(r=-0.5, P=0.004)$ symptoms. There was no correlation between the active ghrelin ratio and the SCOPA-AUT gastrointestinal score in the atypical parkinsonian group $(P=0.6)$ or the control group $(P=0.9)$.

\section{Discussion}

In the present study, patients with MSA showed aberrant ghrelin secretion that was characterized by a low active ghrelin ratio. Furthermore, there was a significant correlation between the reduced active ghrelin ratio and the severity of gastrointestinal symptoms in patients with MSA, indicating that a lower active ghrelin ratio was associated with more gastrointestinal symptoms in MSA. This phenomenon was not observed in patients with progressive supranuclear palsy-Richardson syndrome or corticobasal syndrome.

Experimental data have shown that dopamine and dopamine agonists stimulate the release of active ghrelin from a ghrelin-producing cell line in vitro [20], therefore stimulatory effects of these drugs on ghrelin secretion should be considered in patients with MSA and other atypical parkinsonian disorders. However, levodopa equivalent daily doses were matched for MSA and other atypical parkinsonian groups, thereby controlling for the possibility that anti-parkinsonian medications influenced the results of this study.

Previous studies have shown that patients with MSA frequently exhibit delayed gastric emptying [1] and slow colonic transit [2]. Accumulating evidence suggests that active ghrelin facilitates motility of the gastric antrum [4, 5] and colorectum [21], and unacylated ghrelin may 
counteract the effects of active ghrelin [22, 23]. Therefore, the reduced active ghrelin ratio presented in this study may contribute to compromised motilities of the gastric antrum and colorectum in patients with MSA.

The pathogenic mechanism of aberrant ghrelin secretion in MSA is not yet known. Cholinergic innervation of the gastrointestinal tract is thought to regulate ghrelin secretion in humans [24]. Postmortem examination of MSA patients has revealed that neurodegeneration occurs in vagal autonomic nuclei [25], which provide extrinsic cholinergic innervation to the gastrointestinal tract. Therefore, there may be a link between disruption of the vagal pathway to the gastrointestinal tract and aberrant ghrelin secretion in patients with MSA. Our observation that the active ghrelin ratio was similar in the atypical parkinsonian and control groups suggests that cholinergic innervation to the gastrointestinal tract is relatively well preserved in patients with progressive supranuclear palsy-Richardson syndrome and corticobasal syndrome.

These findings are the first to show that reduced active ghrelin ratio may contribute to the pathogenic mechanism of compromised gastrointestinal motility in patients with MSA. Pharmacological interventions that have therapeutic value in relation to increasing plasma active ghrelin should be considered for gastrointestinal symptoms in patients with MSA.

Acknowledgments This study was supported by a Grant-in-Aid for Scientific Research from the Ministry of Education, Culture, Sports, Science and Technology of Japan (No. 21591109), a Grant for Promotion of Niigata University Research Projects, Grants from the Japan Health Foundation, the Kato Memorial Trust for Nambyo Research, Nestle Nutrition Council, Japan, and the Research Committee for Ataxic Diseases of the Ministry of Health, Welfare, and Labour of Japan. The authors thank Drs. Takanobu Ishiguro, Ayako Ishihara, Yuka Koike, Masahiro Hatakeyama, Maino Yamada, and Fumihiro Yanagimura for their help in this study.

Conflicts of interest The authors state that they have no conflict of interest.

Open Access This article is distributed under the terms of the Creative Commons Attribution License which permits any use, distribution, and reproduction in any medium, provided the original author(s) and the source are credited.

\section{References}

1. Tanaka Y, Kato T, Nishida H, Yamada M, Koumura A, Sakurai T, Hayashi Y, Kimura A, Hozumi I, Araki H, Murase M, Nagaki M, Moriwaki H, Inuzuka T (2012) Is there delayed gastric emptying in patients with multiple system atrophy? An analysis using the (13)C-acetate breath test. J Neurol 259:1448-1452

2. Sakakibara R, Odaka T, Uchiyama T, Liu R, Asahina M, Yamaguchi K, Yamaguchi T, Yamanishi T, Hattori T (2004) Colonic transit time, sphincter EMG, and rectoanal videomanometry in multiple system atrophy. Mov Disord 19:924-929
3. Kojima M, Hosoda H, Date Y, Nakazato M, Matsuo H, Kangawa $\mathrm{K}$ (1999) Ghrelin is a growth-hormone-releasing acylated peptide from stomach. Nature 402:656-660

4. Tack J, Depoortere I, Bisschops R, Delporte C, Coulie B, Meulemans A, Janssens J, Peeters T (2006) Influence of ghrelin on interdigestive gastrointestinal motility in humans. Gut 55:327-333

5. Levin F, Edholm T, Schmidt PT, Gryback P, Jacobsson H, Degerblad M, Hoybye C, Holst JJ, Rehfeld JF, Hellstrom PM, Naslund E (2006) Ghrelin stimulates gastric emptying and hunger in normal-weight humans. J Clin Endocrinol Metab 91: 3296-3302

6. Gilman S, Wenning GK, Low PA, Brooks DJ, Mathias CJ, Trojanowski JQ, Wood NW, Colosimo C, Durr A, Fowler CJ, Kaufmann H, Klockgether T, Lees A, Poewe W, Quinn N, Revesz T, Robertson D, Sandroni P, Seppi K, Vidailhet M (2008) Second consensus statement on the diagnosis of multiple system atrophy. Neurology 71:670-676

7. Litvan I, Agid Y, Calne D, Campbell G, Dubois B, Duvoisin RC, Goetz CG, Golbe LI, Grafman J, Growdon JH, Hallett M, Jankovic J, Quinn NP, Tolosa E, Zee DS (1996) Clinical research criteria for the diagnosis of progressive supranuclear palsy (Steele-Richardson-Olszewski syndrome): report of the NINDSSPSP international workshop. Neurology 47:1-9

8. Boeve BF, Lang AE, Litvan I (2003) Corticobasal degeneration and its relationship to progressive supranuclear palsy and frontotemporal dementia. Ann Neurol 54(Suppl 5):S15-S19

9. Kashihara K, Imamura T (2012) Clinical correlates of anterior and lateral flexion of the thoracolumbar spine and dropped head in patients with Parkinson's disease. Parkinsonism Relat Disord 18:290-293

10. Murashita M, Kusumi I, Inoue T, Takahashi Y, Hosoda H, Kangawa K, Koyama T (2005) Olanzapine increases plasma ghrelin level in patients with schizophrenia. Psychoneuroendocrinology 30:106-110

11. Gambineri A, Pagotto U, Tschop M, Vicennati V, Manicardi E, Carcello A, Cacciari M, De Iasio R, Pasquali R (2003) Antiandrogen treatment increases circulating ghrelin levels in obese women with polycystic ovary syndrome. J Endocrinol Invest 26:629-634

12. Grinspoon S, Miller KK, Herzog DB, Grieco KA, Klibanski A (2004) Effects of estrogen and recombinant human insulin-like growth factor-I on ghrelin secretion in severe undernutrition. J Clin Endocrinol Metab 89:3988-3993

13. Norrelund H, Hansen TK, Orskov H, Hosoda H, Kojima M, Kangawa K, Weeke J, Moller N, Christiansen JS, Jorgensen JO (2002) Ghrelin immunoreactivity in human plasma is suppressed by somatostatin. Clin Endocrinol (Oxford) 57:539-546

14. Vestergaard ET, Hansen TK, Nielsen S, Moller N, Christiansen JS, Jorgensen JO (2005) Effects of GH replacement therapy in adults on serum levels of leptin and ghrelin: the role of lipolysis. Eur J Endocrinol 153:545-549

15. Arai M, Matsumura T, Tsuchiya N, Sadakane C, Inami R, Suzuki T, Yoshikawa M, Imazeki F, Yokosuka O (2012) Rikkunshito improves the symptoms in patients with functional dyspepsia, accompanied by an increase in the level of plasma ghrelin. Hepatogastroenterology 59:62-66

16. Visser M, Marinus J, Stiggelbout AM, Van Hilten JJ (2004) Assessment of autonomic dysfunction in Parkinson's disease: the SCOPA-AUT. Mov Disord 19:1306-1312

17. Schmid SM, Hallschmid M, Jauch-Chara K, Born J, Schultes B (2008) A single night of sleep deprivation increases ghrelin levels and feelings of hunger in normal-weight healthy men. J Sleep Res 17:331-334

18. Tschop M, Wawarta R, Riepl RL, Friedrich S, Bidlingmaier M, Landgraf R, Folwaczny C (2001) Post-prandial decrease of circulating human ghrelin levels. J Endocrinol Invest 24:RC19-21 
19. Calissendorff J, Danielsson O, Brismar K, Rojdmark S (2005) Inhibitory effect of alcohol on ghrelin secretion in normal man. Eur J Endocrinol 152:743-747

20. Iwakura H, Ariyasu H, Hosoda H, Yamada G, Hosoda K, Nakao K, Kangawa K, Akamizu T (2011) Oxytocin and dopamine stimulate ghrelin secretion by the ghrelin-producing cell line, MGN3-1 in vitro. Endocrinology 152:2619-2625

21. Shimizu Y, Chang EC, Shafton AD, Ferens DM, Sanger GJ, Witherington J, Furness JB (2006) Evidence that stimulation of ghrelin receptors in the spinal cord initiates propulsive activity in the colon of the rat. J Physiol 576:329-338

22. Fujimiya M, Ataka K, Asakawa A, Chen CY, Kato I, Inui A (2011) Ghrelin, des-acyl ghrelin and obestatin on the gastrointestinal motility. Peptides 32:2348-2351
23. Hirayama H, Shiina T, Shima T, Kuramoto H, Takewaki T, BF J, Shimizu Y (2010) Contrasting effects of ghrelin and des-acyl ghrelin on the lumbo-sacral defecation center and regulation of colorectal motility in rats. Neurogastroenterol Motil 22: $1124-1131$

24. Maier C, Schaller G, Buranyi B, Nowotny P, Geyer G, Wolzt M, Luger A (2004) The cholinergic system controls ghrelin release and ghrelin-induced growth hormone release in humans. J Clin Endocrinol Metab 89:4729-4733

25. Benarroch EE, Schmeichel AM, Sandroni P, Low PA, Parisi JE (2006) Involvement of vagal autonomic nuclei in multiple system atrophy and Lewy body disease. Neurology 66:378-383 